School of Finance

University of St.Gallen

WHERE DOES INFORMATION PROCESSING IN A

FRAGMENTED MARKET TAKE PlaCE? - EVIDENCE FROM THE SWISS STOCK MARKET AFTER MIFID

AleXANDer KoHler

RICO VON WYSS

WORKING PAPERS ON FinANCE NO. 2012/9

SWISS INSTITUTE OF BANKING AND FINANCE (S/BF - HSG)

JUNE 2012 


\title{
Where does Information Processing in a Fragmented Market Take Place? - Evidence from the Swiss Stock Market after MiFID
}

\author{
Alexander Kohler*and Rico von Wyss ${ }^{\dagger}$
}

This version: June 1, 2012

\begin{abstract}
The implementation of MiFID lead to fragmentation of trading in European equities. We analyze information processing for a sample of Swiss stocks on the Swiss exchange and on Chi-X, the largest multilateral trading facility. According to Hasbrouck information shares, the determination of a leading market is not conclusively possible. By applying an autoregressive conditional intensity (ACI) model that explicitly takes the asynchronous structure of order arrivals into account, we find strong evidence that Chi-X is the leading market in terms of intensity based information shares.
\end{abstract}

Keywords: MiFID, Price Discovery, Multivariate Autoregressive Conditional Intensity.

JEL Classification: G14, G18, C32, C51

\footnotetext{
*Algofin AG, Webergasse 15, 9000 St. Gallen, Switzerland. (corresponding author)

Tel.: $+41-71-5350500$

Fax: +41-71-5350501

Email: alexander.kohler@algofin.ch

${ }^{\dagger}$ University of St. Gallen, Rosenbergstrasse 52, 9000 St. Gallen, Switzerland.

Email: heinrich.vonwyss@unisg.ch

We are grateful to Thomson Reuters for providing data. We also thank Stephan Süss and the participants of the 2011 Topics in Finance seminar for insightful comments.
} 


\section{Introduction}

The implementation of the Markets in Financial Instruments Directive (MiFID) in Europe in 2007 lead to the emergence of several multilateral trading facilities (MTFs). These alternative trading platforms compete with traditional exchanges for trading volume, i.e., for market share. Therefore, the European trading landscape today is similar to the situation in the United States, where the emergence of alternative trading platforms and fragmentation of trading took place over the last decade.

Several studies analyze the effects of fragmentation and come to different conclusions. The two main strands of argumentation in the literature are positive network externalities through consolidated liquidity versus fragmentation leading to higher competition among trading venues. O'Hara and Ye (2011) bring these two strands together with the proposition of a "single virtual market", where different trading venues represent different connections to a virtually consolidated market. However, this argumentation may not be valid for the situation in Europe. Important differences are that under

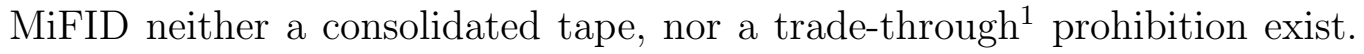
O'Hara and Ye (2011) argue that this lack of a consolidated tape and a trade-through prohibition could prevent the emergence of a "single virtual market" in Europe. An increasing number of studies therefore analyze the implementation of MiFID with a main focus on market quality, e.g., event

\footnotetext{
${ }^{1} \mathrm{~A}$ trade-through is a trade executed at a price, which is higher (lower) than the best available ask (bid) price among all trading venues. Possible explanations for the occurrence of trade-throughs are investors with a speed over price priority (see Kohler and von Wyss (2012)). Another possible explanation for trade-throughs according to Foucault and Menkveld (2008) is that trade-throughs are caused by investors not using smart order routers to route their trades to the trading venue with the best available price.
} 
studies by Foucault and Menkveld (2008), Hengelbrock and Theissen (2009) and Chlistalla and Lutat (2011) and regression analyses by Gresse (2010) and Degryse et al. (2011).

A special aspect in the analysis of fragmented markets is information processing, i.e., how information is incorporated into prices and which trading venue is leading. Two studies that analyze this question in the fragmented European equity market after the implementation of MiFID are Storkenmaier et al. (2012) and Riordan et al. (2011). Storkenmaier et al. (2012) analyze stocks that are traded on the LSE and Chi-X and find for the quote based price discovery higher information shares for Chi-X (58.19\%), than for LSE (41.81\%), although LSE provides more liquidity. Furthermore, they analyze market reactions of LSE and Chi-X to Thomson Reuters newswire messages and find a shift of information processing towards LSE on days where positive news outweigh. Riordan et al. (2011) also report quote based information shares for Chi-X, which are higher $(56.77 \%)$ than for LSE (27.63\%) or other MTFs, like BATS (11.66\%) or Turquoise (3.94\%).

Both studies apply Hasbrouck information shares (see Hasbrouck (1995)) for the attribution of information shares to the different trading venues. Although information shares according to Hasbrouck is a widely used concept, there are two main drawbacks. First, information shares require equidistant data and, therefore, do not take the asynchronous nature of intraday data (e.g., order arrivals or order book changes) into account. Second, if there is contemporaneous correlation in the price innovations across different trading venues, the Hasbrouck information share of a market is not uniquely determined, but given in terms of upper and lower bounds. Typically, these 
bounds cover a wide range, which makes the clear identification of a leading venue impossible.

In this article we also apply Hasbrouck information shares, but extend the analysis by using an autoregressive conditional intensity (ACI) model according to Russell (1999) as a new measure. We are, therefore, able to contribute to the literature on information processing after MiFID since, to our best knowledge, this is the first study analyzing directly the intensity processes in the fragmented European markets after MiFID. We analyze information processing on the Swiss exchange and on Chi-X, which is the largest MTF competing with the Swiss exchange ${ }^{2}$. Our contributions are twofold. First, we use a multivariate intensity model which allows us to investigate the research questions in a framework, which lies beyond the scope of previous studies. By modelling the conditional intensities of the order arrivals on the Swiss exchange and Chi-X, we can exploit the duration structure of the effective order arrivals without the loss of information that results from time aggregation. Therefore, we can incorporate typical characteristics of asynchronous order arrivals and we get unbiased point estimates for the information shares of the two trading venues, rather than just upper and lower bounds. Second, we use a new data set, since, to our best knowledge, this is the first study analyzing information processing for Swiss stocks in the fragmented trading landscape after the implementation of MiFID.

Our results suggest that there are significant cross effects between the in-

\footnotetext{
${ }^{2}$ According to Fidessa (fragmentation.fidessa.com) the Swiss exchange accounted for $50.48 \%$ of total trading volume in 2010 , whereas Chi-X accounted for $12.07 \%$. The MTFs Bats Europe, Turquoise and Nasdaq Europe accounted together for $7.37 \%$ in the same period.
} 
tensity processes of the trading venues. Furthermore, we provide evidence that Chi-X is the leading market in terms of intensity based information processing irrespective of the market capitalization of the stocks.

The remainder of this paper is organized as follows. The next section presents the two methods that are used to analyze information processing for stocks that are traded on multiple trading venues. In Section 2.1 we present information shares according to Hasbrouck (1995). In Section 2.2 we introduce the ACI model according to Russell (1999). Section 3 exhibits the data and estimation details for the two models. Empirical results are presented and discussed in Section 4. Finally, Section 5 concludes.

\section{Measuring Information Processing}

\subsection{The Hasbrouck Information Shares}

Information shares according to Hasbrouck (1995) (HIS) are a widely used measure $^{3}$ for the attribution of the share of price discovery to different trading venues. HIS show for different trading venues "who moves first" (see Hasbrouck (1995)). The basic idea is that prices ${ }^{4}$ of the same financial instrument on different trading venues are closely-linked and can, therefore, be assumed to be cointegrated, i.e., a linear combination of the prices is stationary. We follow in the presentation of the model Hasbrouck (1995), Hasbrouck (2002) and Storkenmaier and Wagener (2011).

If $p_{t}^{\mathrm{SWx}}$ denotes the price on the Swiss exchange in period $t$ and $p_{t}^{\mathrm{CHI}}$ denotes

\footnotetext{
${ }^{3}$ See Bingcheng and Zivot (2010).

${ }^{4}$ The model is applicable to different types of prices, such as bid or ask prices, midquote prices or transaction prices.
} 
the price on Chi-X in the same period for the same financial instrument, then the price vector $p_{t}=\left(p_{t}^{\mathrm{SWx}}, p_{t}^{\mathrm{CHI}}\right)^{\prime}$ is driven by a common random walk component $r_{t}$, i.e.,

$$
p_{t}=r_{t}+\left(\epsilon_{t}^{\mathrm{SWX}}, \epsilon_{t}^{\mathrm{CHI}}\right)^{\prime}
$$

with

$$
r_{t}=r_{t-1}+u_{t}
$$

where $u_{t}$ are uncorrelated with $\mathbf{E}\left(u_{t}\right)=0$ and $\mathbf{E}\left(u_{t}^{2}\right)=\sigma_{u}^{2}$. Based on the cointegration relation there exists a representation as bivariate vector error correction model (VECM) for the price vector $p_{t}$, which is given as follows

$$
\Delta p_{t}=p_{t}-p_{t-1}=\alpha \beta^{\prime} p_{t-1}+\Gamma_{1} \Delta p_{t-1}+\Gamma_{2} \Delta p_{t-2}+\cdots+\Gamma_{T} \Delta p_{t-T}+\epsilon_{t} .
$$

The vector $\beta$ defines the cointegration relation between the two prices and vector $\alpha$ shows how fast prices adjust to deviations from the underlying equilibrium price process. $\Gamma_{i}, i \in\{1, \ldots, T\}$ denote parameter matrices associated with the $i^{\text {th }}$ lag of $\Delta p_{t}$. $\epsilon_{t}$ has zero mean and variance $\Sigma_{\epsilon}$. With $\operatorname{Var}\left(\epsilon_{t}\right)=\Sigma_{\epsilon}$, the variance of the random walk component of the price process $p_{t}$ can be expressed as

$$
\sigma_{u}^{2}=\xi \Sigma_{\epsilon} \xi^{\prime}
$$

where $\xi$ denotes the row vector ${ }^{5}$ of long run impacts of innovations $\epsilon_{t}$. As can be seen from Equation 2.4, both markets contribute to the variance of

\footnotetext{
${ }^{5} \xi$ can be calculated as common row vector of $\beta_{\perp}\left[\alpha_{\perp}^{\prime}\left(I_{n}-\sum_{i=1}^{T} \Gamma_{i}\right) \beta_{\perp}\right]^{-1} \alpha_{\perp}^{\prime}$, where $\perp$ denotes the orthogonal complement and $I_{n}$ denotes a $n$-dimensional identity matrix. See Johansen (1991), Engle and Granger (1987) and Kehrle and Peter (2011).
} 
the random walk component. If $\Sigma_{\epsilon}$ is diagonal, i.e., the innovations $\epsilon_{t}$ exhibit no correlation, the contribution of each market's innovation to the random walk innovation is given by

$$
S^{k}=\frac{\xi_{k}^{2} \Sigma_{\epsilon_{k k}}}{\xi \Sigma_{\epsilon} \xi^{\prime}}
$$

where $S^{k}$ is defined as market $k$ 's information share, $\xi_{k}$ denotes the $k^{\text {th }}$ element of $\xi$ and $\Sigma_{\epsilon_{k k}}$ denotes the $k^{\text {th }}$ diagonal element of $\Sigma_{\epsilon}$.

As price innovations across markets are typically not uncorrelated, two suggestions are given in Hasbrouck (1995) to minimize correlation and limit the information shares. First, shorter time intervals for price aggregation are proposed. As markets will typically react sequentially to events with one market adjusting faster than the other, price aggregation over long time spans will make the adjustment of the leading market and the reaction of the other market look contemporaneous. This effect can be minimized by shortening the observation intervals. In this paper we follow Hasbrouck (2003) and use one-second sampling intervals. Second, upper and lower bounds for the information shares can be calculated as

$$
H I S^{k}=\frac{\left([\xi C]_{k}\right)^{2}}{\xi \Sigma_{\epsilon} \xi^{\prime}}
$$

where $C$ denotes the lower triangular matrix resulting from the Cholesky factorization of $\Sigma_{\epsilon}$. The lower triangular structure of $C$ leads to a hierarchy among the trading venues which results in maximized information shares for the first and minimized information shares for the second trading venue. 
Hasbrouck (1995) suggests to permute $\Sigma_{\epsilon}$ and $\xi$ to get an upper (lower) bound for $H I S^{k}$, denoted by $H I S_{\text {up }}\left(H I S_{\text {low }}\right)$, by setting market $k$ as first (last) market. The mean of the upper and lower bound for HIS is then taken as the measure for the information share of market $k$, i.e.,

$$
H I S^{k}=\frac{H I S_{u p}^{k}+H I S_{l o w}^{k}}{2}
$$

There are two major drawbacks of HIS. As discussed above and stated in Hasbrouck (1995), upper and lower bounds for HIS have to be calculated because of contemporaneous correlation among price innovations. These bounds can diverge considerably ${ }^{6}$, which makes the determination of a leading market in terms of information processing very difficult ${ }^{7}$. Moreover, the upper and lower bound do not present statistical confidence bounds and taking the mean does not result in a statistically meaningful point estimate.

The second and major drawback is that the calculation of HIS requires equidistant data, i.e., for the calculation of information shares a time aggregation is necessary. This time aggregation over equidistant intervals (typically over a one-second or one-minute interval) leads to a loss of information as the irregular structure of the arrival of price changes cannot be taken into account. This problem is even more pronounced with the recent emergence of high frequency trading, which lead to a considerable increase ${ }^{8}$ in electronic messages (for instance quote changes).

\footnotetext{
${ }^{6}$ See Booth et al. (2002), Hupperets and Menkveld (2002) and Kehrle and Peter (2011), who show not only the estimates of HIS, but also estimates of $H I S_{\text {up }}$ and $H I S_{\text {low }}$.

${ }^{7}$ See Grammig and Peter (2011).

${ }^{8}$ See Hendershott et al. (2011).
} 


\subsection{The Autoregressive Conditional Intensity Model}

Russell (1999) proposes a model which focuses on the intensities of the price processes of different trading venues. Several authors applied this model on different research questions. Kehrle and Peter (2011) analyze the price discovery of US-listed Canadian stocks with the home market. Bauwens and Hautsch (2006) present a generalization of Russell's model with a latent factor that jointly influences the individual intensities. Hall and Hautsch (2006, 2007) analyze the intensity processes of order arrivals and order book changes for a sample of five stocks on the Australian stock exchange. All authors emphasize the flexibility of the approach, as it does not require equidistant data, but can be applied on asynchronous data.

Let $K$ denote the number of different trading venues and $N^{k}(t)$ be the counting process associated with the $k^{\text {th }}$ point process, i.e., $N^{k}(t)$ equals the number of $k$-type events up to time $t$. We define the point process $\left\{t_{i}^{k}\right\}_{i=1}^{n^{k}}$ as the sequence of changes of the quoted prices on the Swiss exchange $(k=\mathrm{SWX})$ and on Chi-X $(k=\mathrm{CHI})$. The pooled point process $\left\{t_{i}\right\}_{i=1}^{n}$ is simply the combination of the individual $k$-type point processes and is associated with the counting process $N(t)$. The arrival times of the pooled process and therefore of the individual $k$-type events are assumed to be distinct, i.e., $0<t_{1}<t_{2}<\cdots<t_{n}$. $\mathfrak{F}_{t}$ denotes the filtration of the pooled process and $\lambda^{k}\left(t, \mathfrak{F}_{t}\right)$ the intensity of the $k$-type point process, i.e.,

$$
\lambda^{k}\left(t, \mathfrak{F}_{t}\right)=\lim _{\Delta \rightarrow 0} \frac{\mathbb{P}\left\{N^{k}(t+\Delta)-N^{k}(t)>0, N^{k^{\prime}}(t+\Delta)-N^{k^{\prime}}(t)=0 \mid \mathfrak{F}_{t}\right\}}{\Delta}
$$

where $k \neq k^{\prime}$. This means $\lambda^{\mathrm{SWX}}\left(t, \mathfrak{F}_{t}\right)$ and $\lambda^{\mathrm{CHI}}\left(t, \mathfrak{F}_{t}\right)$ are the instantaneous 
probabilities at time $t$ of a change in the order book of the Swiss exchange and Chi-X, respectively.

In the extended ACI model of Russell (1999) the conditional intensity function of process $k$ can be written as

$$
\lambda^{k}\left(t, \mathfrak{F}_{t}\right)=\lambda_{0}^{k} \psi_{t}^{k} \phi_{t}^{k}
$$

where $\lambda_{0}^{k}$ denotes a baseline intensity function, $\psi_{t}^{k}$ equals the actual intensity process and $\phi_{t}^{k}$ captures seasonal effects. The pooled bivariate intensity process $\psi_{t}=\left(\psi_{t}^{\mathrm{SWX}}, \psi_{t}^{\mathrm{CHI}}\right)^{\prime}$ itself is parametrized as

$$
\psi_{t}=\exp \left(\tilde{\psi}_{N(t)}+z_{N(t)}^{\prime} \mu^{k}\right)
$$

where $\tilde{\psi}_{i}$ is a vector autoregressive moving average (VARMA) process, $z=$ $\left(z_{1}, z_{2}, \ldots, z_{n}\right)^{\prime}$ denotes a vector of explanatory variables for market characteristics and $\mu^{k}$ is the coefficient vector of $z$. Hall and Hautsch $(2006,2007)$ show the importance of the incorporation of the current state of the market in the modeling of the intensity processes. Moreover, they show a significant improvement of the goodness of fit of the model. The VARMA process $\tilde{\psi}_{i}$ is given by

$$
\tilde{\psi}_{i}=\sum_{k \in\{\mathrm{SWX}, \mathrm{CHI}\}}\left(a^{k} \epsilon_{i-1}^{k}+B \tilde{\psi}_{i-1}\right) y_{i-1}^{k},
$$

where $a^{k}$ are $(2 \times 1)$ coefficient vectors and $B$ denotes a $(2 \times 2)$ coefficient matrix. $y_{i}^{k}$ are variables, indicating where the $i^{\text {th }}$ event occurred, i.e., $y_{i}^{\mathrm{SWX}}=1$ if the $i^{t h}$ event occurred on the Swiss exchange and zero otherwise and $y_{i}^{\mathrm{CHI}}=1$ if the $i^{\text {th }}$ event occurred on Chi-X and zero otherwise. Due to the autoregres- 
sive structure of the intensity process the model is called an autoregressive conditional intensity (ACI) model. In the terminology of Russell (1999), Equation 2.11 determines an $\mathrm{ACI}(1,1)$ model as it contains one autoregressive and one moving average component. Extending the model to a higher order $\operatorname{ACI}(p, q)$ model is done straightforward by including the respective number of lags of $\epsilon_{i}^{k}$ and $\tilde{\psi}_{i}$. The vectors $a^{k}=\left(a_{1}^{k}, a_{2}^{k}\right)^{\prime}, k \in\{\mathrm{SWX}, \mathrm{CHI}\}$ measure the impact of innovations of the point process of market $k, \epsilon_{i}^{k}$, on the intensity process of the Swiss exchange by $a_{1}^{k}$ and on the intensity process of Chi-X by $a_{2}^{k}$. It is therefore clear that the $k$-type intensity process $\psi_{t}^{k}$ and the $k$-type conditional intensity function $\lambda^{k}\left(t, \mathfrak{F}_{t}\right)$ are not only influenced by $k$-type innovations, but also by innovations of the other point process, i.e., by quote changes of the other trading venue.

The off-diagonal elements of the autoregressive coefficient matrix $B$ are set to zero following Russell (1999), Bauwens and Hautsch (2006) and Kehrle and Peter (2011), which makes

$$
B=\left(\begin{array}{ll}
b^{\mathrm{SWX}} & 0 \\
0 & b^{\mathrm{CHI}}
\end{array}\right)
$$

a diagonal matrix and Equation 2.11 a diagonal $\mathrm{ACI}(1,1) \operatorname{model}^{9}$. This restriction implies that only the vectors $a^{k}$ cause cross effects of an innovation on the intensity of the other point process.

The innovation in Equation 2.11 is based on the compensator, which is given

\footnotetext{
${ }^{9}$ See the terminology used by Russell (1999). In the remainder of this paper the term ACI model is used as synonym for a diagonal ACI(1,1) model.
} 
by

$$
\Lambda^{k}\left(t_{i-1}^{k}, t_{i}^{k}\right)=\int_{t_{i-1}^{k}}^{t_{i}^{k}} \lambda^{k}\left(u, \mathfrak{F}_{u}\right) d u=\sum_{j} \int_{\tilde{t}_{j}}^{\tilde{t}_{j+1}} \lambda^{k}\left(u, \mathfrak{F}_{u}\right) d u
$$

i.e., by the piecewise integration of the conditional $k$-type intensity $\lambda^{k}\left(t, \mathfrak{F}_{t}\right)$ over all inter-event intervals $\left[\tilde{t}_{j}, \tilde{t}_{j+1}\right]$ with $t_{i-1}^{k}<\tilde{t}_{j}<\tilde{t}_{j+1} \leq t_{i}^{k}$. As in Equation 2.11 innovations of both point processes have an impact on the conditional $k$-type intensity $\lambda^{k}\left(t, \mathfrak{F}_{t}\right)$, the $k$-type compensator $\Lambda^{k}\left(t_{i-1}^{k}, t_{i}^{k}\right)$ also depends on the cross effects of the other point process.

According to the multivariate random time change theorem ${ }^{10}$ the processes $\Lambda^{k}\left(0, t_{i}^{k}\right), i=1, \ldots, n^{k}, k \in\{\mathrm{SWX}, \mathrm{CHI}\}$ are Poisson processes with unit intensity. As increments of a Poisson process, $\Lambda^{k}\left(t_{i-1}^{k}, t_{i}^{k}\right)$ are iid standard exponentially distributed. We follow Russell (1999) and define the innovations in the VARMA process by

$$
\epsilon_{i}^{k}=1-\Lambda^{k}\left(t_{i-1}^{k}, t_{i}^{k}\right)
$$

The compensator $\Lambda^{k}\left(t_{i-1}^{k}, t_{i}^{k}\right)$ expresses the expected number of events within the interval $\left[t_{i-1}^{k}, t_{i}^{k}\right]$. Hence, a positive innovation term $\epsilon_{i}^{k}$ implies that the arrival rate was underestimated and a negative innovation term implies an overestimation of the arrival rate. As can be seen from Equation 2.11, an underestimation of the arrival rate $\left(\epsilon_{i}^{k}>0\right)$ leads to an increase in the intensity process $\psi_{t}^{k}$ and the $k$-type conditional intensity function $\lambda^{k}\left(t, \mathfrak{F}_{t}\right)$ and an overestimation $\left(\epsilon_{i}^{k}<0\right)$ to a decrease. As stated in Bauwens and Hautsch (2006), according to the definition the innovation term depends only on the time between past events and on past intensities, which eases computation.

\footnotetext{
${ }^{10}$ See also Bowsher (2007), Bauwens and Hautsch (2006) and Brown and Nair (1988).
} 
The log-likelihood function of the ACI model can be expressed in terms of the intensity function solely (see Bauwens and Hautsch (2006) and Karr (1991)). For the bivariate point process the $\log$-likelihood function $\log L(\theta)$ is given by

$$
\log L(\theta)=\sum_{k \in\{\mathrm{SWX}, \mathrm{CHI}\}} \sum_{i=1}^{n}\left(-\Lambda^{k}\left(t_{i-1}, t_{i}\right)+y_{i}^{k} \log \lambda^{k}\left(t_{i}, \mathfrak{F}_{t_{i}}\right)\right)
$$

where $\theta$ denotes the vector of the model parameters. We follow Kehrle and Peter (2011) and apply robust estimators ${ }^{11}$ for the standard errors of the components of $\theta$. These robust estimators for the standard errors are consistent with quasi-maximum likelihood estimators for $\theta$ in case of a misspecification of the model.

The empirical distribution of the residuals of the estimated innovations $\tilde{\epsilon}_{i}^{k}=$ $\Lambda^{k}\left(t_{i-1}^{k}, t_{i}^{k}\right)$ is then compared to the theoretical distribution iid $\operatorname{Exp}(1)$ for testing the model specification. We follow previous studies (e.g., Russell (1999), Bauwens and Hautsch (2006), Kehrle and Peter (2011) and Hall and Hautsch $(2006,2007))$ and report summary statistics of the series of estimated residuals and a Ljung-Box Test with 20 lags $\left(L B_{20}\right)$ for autocorrelation. Additionally, a test for overdispersion is applied, which follows Engle and Russell (1998), who propose the test statistic $O D^{k}=\sqrt{\frac{n^{k}}{8\left(\sigma_{\tilde{\epsilon}}^{k}\right)^{2}}}$, where $n^{k}$ denotes the number of $k$-type residuals and $\left(\sigma_{\tilde{\epsilon}}^{k}\right)^{2}$ the empirical variance. $O D^{k}$ is asymptotically standard normally distributed under the null hypoth$\operatorname{esis}\left(\tilde{\epsilon}_{i}^{k} \sim \operatorname{Exp}(1)\right)$.

\footnotetext{
${ }^{11}$ The robust variance-covariance matrix of the components of $\theta$ is calculated following Kehrle and Peter (2011) as $\Sigma_{\tilde{\theta}}=H^{-1} \mathbf{E}\left[\left(\frac{\delta \log L}{\delta \theta}\right)\left(\frac{\delta \log L}{\delta \theta}\right)\right] H^{-1}$, where $H$ denotes the estimator of the Hessian matrix.
} 
As we are particularly interested in the cross effects of the intensity processes of the two markets, we follow Kehrle and Peter (2011) and calculate intensity based information shares for the two trading venues $\left(I I S^{k}, k \in\{\mathrm{SWX}, \mathrm{CHI}\}\right)$ based on the respective impulse response functions. We define the intensity based information share as

$$
I I S^{\mathrm{SWX}}=\frac{\frac{\left|a_{2}^{\mathrm{SWX}}\right|}{\left|a_{2}^{\mathrm{CHI}}\right|}}{\frac{\left|a_{1}^{\mathrm{CHI}}\right|}{\left|a_{1}^{\mathrm{SWX}}\right|}+\frac{\left|a_{2}^{\mathrm{SWX}}\right|}{\left|a_{2}^{\mathrm{CHI}}\right|}} \quad \text { and } \quad I I S^{\mathrm{CHI}}=\frac{\frac{\left|a_{1}^{\mathrm{CHI}}\right|}{\left|a_{1}^{\mathrm{SWX}}\right|}}{\frac{\left|a_{1}^{\mathrm{CHI}}\right|}{\left|a_{1}^{\mathrm{SWX}}\right|}+\frac{\left|a_{2}^{\mathrm{SWX}}\right|}{\left|a_{2}^{\mathrm{CHI}}\right|}}
$$

which is the ratio of the absolute impact ${ }^{12}$ of a cross effect (e.g., $\left|a_{2}^{\mathrm{SWX}}\right|$ denotes the absolute impact of an innovation shock at Swiss exchange on ChiX's intensity) relative to the absolute impact of a shock in the same market (e.g., $\left|a_{2}^{\mathrm{CHI}}\right|$ denotes the absolute impact of an innovation shock at Chi-X on Chi-X's intensity). This measure is then standardized by $\frac{\left|a_{1}^{\mathrm{CHI}}\right|}{\left|a_{1}^{\mathrm{SWX}}\right|}+\frac{\left|a_{2}^{\mathrm{SWx}}\right|}{\left|a_{2}^{\mathrm{CHI}}\right|}$ to lie between zero and one. Higher values of $I I S^{\mathrm{SWx}}$ indicate that shocks in the point process of the Swiss exchange have a relatively larger absolute effect on Chi-X's intensity process and vice versa. The delta method is applied to calculate standard errors of $I I S^{\mathrm{SWX}}$ and $I I S^{\mathrm{CHI}}$.

\section{Data and Estimation}

We use quote data from the Thomson Reuters Tick History database for 28 Swiss stocks which are traded on the Swiss exchange and on Chi-X. Table 1

\footnotetext{
${ }^{12}$ In contrast to the definition of $I I S$ in Kehrle and Peter (2011), we take the absolute values of $a^{k}$ for the calculation of $I I S$, as we do not discard negative values for the coefficients $a^{k}$, i.e., we allow a shock in one market to have a negative impact on the intensity of another market.
} 
gives the company names and ticker symbols of the stocks in our sample.

[Insert Table 1 here]

The quote data contains changes in the limit order book of the Swiss exchange and Chi-X on the best bid and ask level and is timestamped to the millisecond.

\subsection{Estimation of Hasbrouck Information Shares}

For the calculation of Hasbrouck Information Shares we build one-second snapshots $^{13}$ of historical order books containing the best bid and ask price. Based on the series of midprices ${ }^{14}$ the VECM model according to Equation 2.3 is estimated with $T=300$ lags, i.e., with a memory of 5 minutes. As for every lag $i$ a $(2 \times 2)$ matrix $\Gamma_{i}$ has to be estimated, the model includes roughly $2 \times 2 \times 300=1,200$ coefficients. In order to reduce the complexity we follow Hasbrouck (2003) and use quadratic distributed lags over lags 1 - 10, $11-20$ and $21-30$ and constant coefficients over lags $31-60,61-120$ and 121 - 300. Upper $\left(H I S_{\text {up }}\right)$ and lower $\left(H I S_{\text {low }}\right)$ bounds for the information shares are calculated on a daily basis and HIS is set to the arithmetic mean of the bounds, i.e.,

$$
H I S^{k}=\frac{H I S_{u p}^{k}+H I S_{l o w}^{k}}{2}, k \in\{\mathrm{SWX}, \mathrm{CHI}\} .
$$

\footnotetext{
${ }^{13}$ One second sampling intervals are also used by Hasbrouck (2003), Hendershott and Jones (2005) and Tse et al. (2006).

${ }^{14}$ Erroneous quotes are filtered by applying a rule that discards all midprices, where the deviation between the prices exceeds $5 \%$.
} 


\subsection{Estimation of Intensity Based ACI Model}

For the determination of the intensity processes we build point processes for the two trading venues based on the interarrival times between two consecutive quote changes, denoted by $\tau_{i}^{k}=t_{i}^{k}-t_{i-1}^{k}$, where $k=$ SWX denotes a quote change in the limit order book of the Swiss exchange and $k=\mathrm{CHI}$ in the limit order book of Chi-X. The two series of individual interarrival times are then combined to the pooled series of interarrival times denoted by $\tau_{i}$. Subsequently, overnight spells and quote changes before 9:30am (CET) and after 4:30pm (CET) are removed to eliminate any disturbances from opening and closing and, as the simultaneous arrival of two quote changes is not permitted in the model, quote changes with the same timestamp are skipped. Furthermore, we use price marks ${ }^{15}$ for the thinning of the processes following Engle and Russell (1997), Bauwens and Hautsch (2006) and Kehrle and Peter (2011). First, we calculate the mean midquote change per day. Second, we retain quote changes of the individual series of interarrival times of the two venues where the absolute cumulative price change exceeds the threshold of 50 times the mean midquote change per day, which is consistent with previous studies ${ }^{16}$. With the thinned processes, we can disentangle information driven price changes from pure noise.

Following Kehrle and Peter (2011) we use polynomial and trigonometric time functions according to Eubank and Speckman (1990) for the adjustment of

\footnotetext{
${ }^{15}$ Price marks are information that is observed simultaneously with the arrival of a price change, e.g., the change in the midquotes.

${ }^{16}$ The chosen threshold leads to a median threshold of 0.06 Swiss Francs, which lies between the average thresholds used by Kehrle and Peter (2011) and Bauwens and Hautsch (2006). Hall and Hautsch (2006) use a thinning algorithm based on the order volume which skips $94.3 \%$ of all observations in their initial sample.
} 
intraday patterns of the pooled process. The interarrival times of the pooled process $\left(\tau_{i}\right)$ are regressed on polynomial and trigonometric time functions according to the following regression equation

$$
\tau_{i}=\beta_{0}+\sum_{j=1}^{d} \beta_{j}^{p} t_{i}^{j}+\sum_{j=1}^{\delta}\left[\beta_{j}^{c} \cos \left(j t_{i}\right)+\beta_{j}^{s} \sin \left(j t_{i}\right)\right]+\epsilon_{i} .
$$

We select the number of polynomial $(d)$ and trigonometric $(\delta)$ regressors as the combination that minimizes the generalized cross-validation criteria $G C V$ given by

$$
G C V=\frac{n R S S}{(n-2 \delta-d-1)^{2}},
$$

where $R S S$ is the residual sum of squares, $n$ the number of observations and $G C V$ is evaluated for $d \in\{1, \ldots, 5\}$ and $\delta \in\{1, \ldots, 5\}$. Figure 1 shows a typical intraday pattern of interarrival times, which follows a $\cap$-shape, i.e., the time periods between two consecutive price changes are lower at the beginning and the end of the trading day and exhibit a maximum around noon.

\section{[Insert Figure 1 here]}

Additionally any linear trend, which would indicate a general increase or decrease in interarrival times due to a generally decreasing or increasing market activity, is removed. The series of the adjusted pooled process of interarrival times is then calculated by the division of the interarrival times of the pooled process $\left(\tau_{i}\right)$ by the typical intraday pattern $\left(\phi_{i}\right)$, which results from Equation 3.2, i.e.,

$$
\tilde{\tau}_{i}=\frac{\tau_{i}}{\phi_{i}}
$$


Based on the adjusted interarrival times $\tilde{\tau}_{i}$ the $\mathrm{ACI}(1,1)$ model in Equation 2.11 is estimated by the maximization of the log-likelihood function given by Equation 2.14 with the $\mathrm{BHHH}^{17}$ algorithm and numerical derivatives ${ }^{18}$.

The baseline intensity function $\lambda_{0}^{k}$ in Equation 2.9 is modeled in dependence of a baseline intensity specific to the trading venue and the backward recurrence time associated with the point process of the trading venue. In detail, we follow Bauwens and Hautsch (2006) and Hall and Hautsch (2007) and model $\lambda_{0}^{k}$ as a Burr-type hazard function, i.e.,

$$
\lambda_{0}^{k}(t)=\exp \left(\omega^{k}\right) \frac{U^{k}(t)^{\gamma_{1}^{k}-1}}{1+\gamma_{2}^{k} U^{k}(t)^{\gamma_{1}^{k}}},
$$

where $U^{k}(t)$ denotes the backward recurrence time at time $t$ of the $k^{\text {th }}$ point process, i.e., in Equation $3.5 U^{k}(t)$ is given and $\omega^{k}, \gamma_{1}^{k}$ and $\gamma_{2}^{k}$ have to be estimated. We restrict the baseline intensity function $\lambda_{0}^{k}$ of process $k$ to depend only on its own backward recurrence time ${ }^{19}$. Therefore, we can ensure that cross effects are captured by the vectors $a^{k}$ solely.

For the incorporation of the current state of the market by vector $z$, the current liquidity, we follow Hall and Hautsch (2006) and include the relative spread of the respective market $\left(R S^{k}\right)$, the logarithm of the cumulated volume of the bid and ask side of the respective market $\left(B V^{k}, A V^{k}\right)$, the cumulated midquote price change $\left(M Q_{15}^{k}\right)$ and the volatility $\left(V O L_{15}^{k}\right)$ over the last 15 minutes, $k \in\{\mathrm{SWX}, \mathrm{CHI}\}$. This choice of variables reflects the

\footnotetext{
${ }^{17}$ See Berndt et al. (1974).

${ }^{18}$ See also Engle and Russell (1997) and Russell (1999)

${ }^{19}$ Bauwens and Hautsch (2006) propose a parameterization that includes also the backward recurrence time of the other $k-1$ processes. However, in the numerical estimation they restrict the Burr-type hazard functions to depend on the backward recurrence time of the own process solely.
} 
multi-dimensionality of liquidity ${ }^{20}$.

\section{Empirical Results}

We present descriptive statistics for the series of adjusted order book changes for the Swiss exchange and Chi-X in Table 2.

[Insert Table 2 here]

The average number of midquote price changes $Q$ per stock for the Pooled Sample during the sample period January 1 to March 31, 2010 is 1,542 for the Swiss exchange and 1,379 for Chi-X with mean price durations of 35 and 56 minutes, respectively. Bauwens and Hautsch (2006) report mean price durations in the range of $12-20$ minutes for their sample of five highly liquid NYSE stocks, which is comparable to our findings for the first quartile of subsample Stocks L where we find average price durations in the range of $13-29$ minutes. Overall, the number of midquote price changes is higher on the Swiss exchange and for the stocks in subsample Stocks L, where this difference is significant for the Swiss exchange.

\subsection{Empirical Results from HIS}

Table 3 shows the average daily HIS per stock for the Pooled Sample and for the subsamples Stocks L and Stocks S.

\section{[Insert Table 3 here]}

\footnotetext{
${ }^{20}$ Liquidity is understood as multi-dimensional concept and, therefore, multiple measures are used for capturing different dimensions of liquidity. See Chordia et al. (2000) and Chordia et al. (2001).
} 
The mean information share of the Swiss exchange for the Pooled Sample equals $53.25 \%$, which would indicate that the Swiss exchange has a higher information share than Chi-X. However, the median information share of the Swiss exchange is $48.16 \%$, which is slightly below $50 \%$. The problem of clearly identifying the leading venue in terms of the information share arises with the consideration of the upper and lower bounds of HIS. Figure 2 shows the estimated HIS together with the upper and lower bounds $H I S_{u p}$ and $H I S_{\text {low }}$, respectively.

\section{[Insert Figure 2 here]}

As already stated, $H I S^{\mathrm{SWx}}$ and $H I S^{C H I}$ are calculated as mean of the respective upper and lower bounds $H I S_{u p}$ and $H I S_{\text {low }}$. This means that for the Pooled Sample the information share of the Swiss exchange lies between $40.47 \%\left(H I S_{\text {low }}^{\mathrm{SWX}}\right)$ and $66.04 \%\left(H I S_{u p}^{\mathrm{SWX}}\right)$ and the information share of ChiX between $33.96 \%\left(H I S_{\text {low }}^{\mathrm{CHI}}\right)$ and $59.53 \%\left(H I S_{u p}^{\mathrm{CHI}}\right)$, respectively. No trading venue has an information share which lies clearly above or below $50 \%$, which makes the identification of the leading trading venue for the Pooled Sample impossible.

The same holds true for subsample Stocks L. Although the mean and the median information share of Chi-X are larger than 50\%, according to the upper and lower bounds, a clear identification of the leading venue is not possible as the mean of $H I S_{\text {low }}^{\mathrm{SWX}}$ lies with $27.92 \%$ below $50 \%$ and the mean of $H I S_{u p}^{\mathrm{SWX}}$ with $60.33 \%$ above $50 \%$.

For subsample $\mathrm{S}$ the mean and median information share is higher for the Swiss exchange than for Chi-X with a mean information share of $62.38 \%$ 
and a median information share of $60.92 \%$ for the Swiss exchange. For this subsample the range between upper and lower bounds of HIS are disjoint, which allows the identification of the Swiss exchange as trading venue "who moves first".

Overall, the question which trading venue is actually leading in terms of Hasbrouck information shares cannot be answered conclusively. For the large caps some evidence is found that Chi-X is the leading market, which would confirm the results of Storkenmaier and Wagener (2011) and Riordan et al. (2011). However, upper and lower bounds of HIS do not allow a clear identification of the leading venue. For the small caps evidence suggests that the Swiss exchange is the leading market.

\subsection{Empirical Results from ACI Model}

We present the estimation results for the bivariate $\mathrm{ACI}(1,1)$ model outlined in Section 2.2 in Table 4. Estimation is done by the maximization ${ }^{21}$ of the log-likelihood function given in Equation 2.14.

\section{[Insert Table 4 here]}

As can be seen from Table 4 , the estimates of $a_{1}^{\mathrm{SWX}}$ and $a_{2}^{\mathrm{CHI}}$ are positive for all stocks, which indicates positive autocorrelation in the intensities of the two trading venues. The coefficients are significantly positive for $64 \%$ and $71 \%$ of the stocks in the Pooled Sample, for $71 \%$ and $79 \%$ of the stocks in subsample Stocks L and for $57 \%$ and $64 \%$ of the stocks in subsample Stocks

\footnotetext{
${ }^{21}$ Maximization is performed without constraints for $\omega^{k}$ and $a^{k} . b^{k}$ are constraint to lie between 0 and 1 to ensure stationarity of the VARMA process defined in Equation 2.11. $\gamma^{k}$ are constraint to be positive.
} 
S. An underestimation of the intensity on the Swiss exchange $\left(\epsilon_{i}^{\mathrm{SWX}}>0\right)$, therefore, leads to an increase in the Swiss exchange's intensity and the same holds true for Chi-X where an underestimation of the intensity $\left(\epsilon_{i}^{\mathrm{CHI}}>0\right)$ also increases Chi-X's intensity.

The coefficients $a_{2}^{\mathrm{SWX}}$ and $a_{1}^{\mathrm{CHI}}$ are positive and significant for the majority of the stocks of the Pooled Sample, which means that there are significant spillover effects between the different intensity processes ${ }^{22}$. Furthermore, the first quartiles for both coefficients are positive. For subsample Stocks L the mean of the coefficient $a_{1}^{\mathrm{CHI}}$ is negative, however, the median and the first quartile are positive. The coefficients are significant for $64 \%$ and $71 \%$ of the stocks in subsample Stocks L. This means that an intensity shock on one trading venue directly affects the intensity on the other trading venue, e.g., an underestimation of the Swiss exchange's intensity $\left(\epsilon_{i}^{\mathrm{SWX}}>0\right)$ leads to an increase of the intensity on Chi-X and vice versa.

The persistence of innovation shocks, measured with the coefficients $b^{\mathrm{SWX}}$ and $b^{\mathrm{CHI}}$, is high and significant for the majority of the stocks. The mean of $b^{\mathrm{SWX}}$, which measures the persistence of the innovation shocks on the Swiss exchange, equals 0.906 for the Pooled Sample and 0.874 and 0.938 for Stocks L and Stocks S, respectively. For Chi-X the persistence is similar with $b^{\mathrm{CHI}}=0.890$ for the Pooled Sample and 0.935 and 0.844 for Stocks L and Stocks S, respectively. These findings are consistent with findings from other authors (e.g., Engle and Russell (1998) and Kehrle and Peter (2011)).

\footnotetext{
${ }^{22}$ Similar findings are documented in other studies using the ACI model, e.g., Kehrle and Peter (2011), Bauwens and Hautsch (2006) and Hall and Hautsch (2006, 2007).
} 
The baseline intensity functions show rather stable coefficients $\gamma_{1}^{k}$ for the dependence on the backward recurrence time $U^{k}(t)$, where both Burr-type hazard functions have a positive but decreasing slope, which means that the baseline intensity $\lambda_{0}^{k}(t)$ increases between two $k$-type events. These findings correspond to the results of Bauwens and Hautsch (2006), who estimate very similar coefficients $\gamma_{1}^{k}$ for their backward recurrence functions. There is considerable cross-sectional variability in the coefficients $\omega^{k}$, which reflects the variability in the baseline intensity functions among the different stocks. We control for the current state of the market and liquidity situation by incorporating the five state variables relative spread $\left(R S^{k}\right)$, logarithm of the cumulated volume of the bid and ask side $\left(B V^{k}, A V^{k}\right)$, cumulated midquote price change $\left(M Q_{15}^{k}\right)$ and volatility $\left(V O L_{15}^{k}\right)$ over the last 15 minutes, $k \in$ $\{\mathrm{SWX}, \mathrm{CHI}\}$. Table 5 shows the estimation results for the impact of the state variables.

[Insert Table 5 here]

The coefficient of $R S^{k}$ is negative and significant for the majority of the stocks for the Swiss exchange and positive for Chi-X. The coefficients for the cumulated depth on the other hand are positive and predominantly significant for the Swiss exchange and negative for Chi-X. This means high liquidity on the Swiss exchange increases intensity on the Swiss exchange while high liquidity on Chi-X is associated with decreasing intensity on Chi-X.

The coefficients of the cumulated midquote price change over the last 15 minutes are negative for both trading venues and both subsamples meaning that a recent increase of the midquote price is associated with a decrease of 
the intensity of the two trading venues. This corresponds to the findings of Hall and Hautsch (2006) who find evidence that positive midquote returns decrease the overall intensity on the ask side of the order book, while increasing the intensity of the bid side of the order book. A possible reason for the net negative effect of recent midquote returns and intensity, which is also discussed in Hall and Hautsch (2006), could be liquidity considerations which lead to an overall decrease of the intensity of order book changes after a significant midquote change.

Findings for recent volatility are mixed for the different stocks and subsamples. Overall, the median coefficients for $V O L_{15}$ tend to be positive (e.g., for Chi-X in the Pooled Sample and in subsample Stocks S and for both trading venues for subsample Stocks L). This is consistent with findings from Hall and Hautsch $(2006,2007)$ who also find positive relations between past volatility and intensity processes.

Hall and Hautsch (2007) show that including state variables that describe the current state of the market significantly improves residual diagnostics, which are displayed in Table 6 for the three subsamples.

[Insert Table 6 here]

If the model is correctly specified, the residuals $\tilde{\epsilon}$ should follow an iid $\operatorname{Exp}(1)$ distribution, i.e., the mean of the empirical residuals and their standard deviation should be equal to 1 . Table 6 shows summary and test statistics for the empirical residuals of the Pooled Sample and for the two subsamples. The mean and median of $\tilde{\epsilon}_{i}^{k}$ are close to 1 for the Swiss exchange and Chi-X for both subsamples. The average standard deviation of the residuals $\sigma_{\tilde{\epsilon}}$ is 
0.76 and 0.75 for the Swiss exchange and for Chi-X, respectively, which indicates that the residuals are slightly underdispersed. This is consistent with the test statistic for overdispersion $O D^{k}$, which is negative and indicates an underdispersion. As proxy for the iid property, we present two test statistics for autocorrelation, namely the first order autocorrelation coefficients $A C_{1}^{k}$ and the Ljung-Box test statistic $L B_{20}^{k}$. While $A C_{1}^{k}$ should be close to zero, the critical value for $L B_{20}^{k}$ equals 37.57 on a $99 \%$ confidence level. Both test statistics indicate that the residuals exhibit some autocorrelation, where the degree of autocorrelation for the residuals Chi-X is smaller with a mean $A C_{1}^{\mathrm{CHI}}$ of 0.01 and a mean $L B_{20}^{\mathrm{CHI}}$ of 36.70 . The results from the residual diagnostics are consistent for the full sample and the two subsamples. Overall, the model fit is comparable to previous studies using autoregressive conditional intensity models, e.g., Hall and Hautsch (2006, 2007) and Kehrle and Peter (2011).

Based on the estimated ACI $(1,1)$ model we calculate intensity based information shares for the Pooled Sample and the two subsamples. Table 7 gives the results.

[Insert Table 7 here]

The intensity based information share for Chi-X equals $63.4 \%$ in terms of the mean and $66.4 \%$ in terms of the median which means that for the Pooled Sample Chi-X is the leading market in terms of the intensity based information share. The lead of Chi-X is highly significant for $42.9 \%$ of the Pooled Sample, whereas the lead of the Swiss exchange is only significant for $3.6 \%$ of the stocks. These findings are supported by the analysis of the two sub- 
samples. For Stocks L the mean of $I I S^{\mathrm{CHI}}$ equals $62.4 \%$ and for $57.1 \%$ of the stocks in subsample Stocks L the lead of Chi-X is highly significant. The same holds true for subsample Stocks $\mathrm{S}$ with a mean IIS ${ }^{\mathrm{CHI}}$ of $64.4 \%$. However, the lead of Chi-X is only significant at the $1 \%$ level for $28.6 \%$ of the stocks. There is no stock in subsample Stocks $\mathrm{S}$ for which the Swiss exchange is significantly leading at the $1 \%$ or $5 \%$ level.

Overall, we find strong evidence that Chi-X is the leading market in terms of the intensity based information shares, which, in contrast to the Hasbrouck information shares, take the effective duration structure of the order book changes into account. Although the first quartiles of $I I S^{\mathrm{CHI}}$ lie below $50 \%$ for the Pooled Sample and subsample Stocks L, the mean estimates, which in case of the intensity based information shares are point estimates for the true values, lie well above the $50 \%$ threshold and are confirmed by respective significance tests.

The findings from the analysis of the intensity based information shares confirm our findings from the Hasbrouck information shares for subsample Stocks $\mathrm{L}$, which suggested that Chi-X is the leading trading venue. The intensity based information shares also confirm the lead of Chi-X for the second subsample Stocks S, where Hasbrouck information shares suggested a lead of the Swiss exchange. Overall, by taking the effective duration structure into account we calculated unbiased point estimates for the information share, which suggest that Chi-X is the leading market in terms of intensity based information processing irrespective of the market capitalization of the stocks. 


\section{Conclusion}

The exchange landscape in Europe changed fundamentally with the implementation of MiFID in 2007. The emergence of several MTFs lead to a fragmentation of trading in European equities. A key question when a stock is traded in a fragmented market is, where information is processed, i.e., which trading venue is leading in incorporating new information.

Previous studies analyzed information processing after MiFID with the well known Hasbrouck information shares. We also apply Hasbrouck information

shares with inconclusive results. Evidence suggests that Chi-X is the leading trading venue for larger stocks, whereas for smaller stocks the Swiss exchange is still leading. However, overall the clear identification of the leading venue according to Hasbrouck information shares is not possible. This finding stems from the fact that Hasbrouck information shares do not result in a point estimate of the information shares, but rather in upper and lower bounds, which differ significantly.

In this article a new method for the analysis of information processing is used by the calculation of intensity based information shares. By applying an autoregressive conditional intensity model, we calculate intensity based information shares, which take the effective irregular duration structure of order book changes into account. Furthermore, the autoregressive intensity model allows to calculate statistically meaningful point estimates for the information shares of the respective trading venues.

We find significant cross effects between the intensity processes of the Swiss exchange and Chi-X. Furthermore, we provide evidence that Chi-X is the 
leading market in terms of intensity based information processing irrespective of the market capitalization of the stocks. 


\section{References}

Bauwens, L. and Hautsch, N. (2006). Stochastic Conditional Intensity Processes. Journal of Financial Econometrics, 4(3):450-493.

Berndt, E. K., Hall, B. H., Hall, R. E., and Hausman, J. A. (1974). Estimation and Inference in Nonlinear Structural Models. Annuals of Economic and Social Measurement, 3(4):653-665.

Bingcheng, Y. and Zivot, E. (2010). A Structural Analysis of Price Discovery Measures. Journal of Financial Markets, 13(1):1-19.

Booth, G. G., Lin, J., Martikainen, T., and Tse, Y. (2002). Trading and Pricing in Upstairs and Downstairs Stock Markets. Review of Financial Studies, 15(4):1111-1135.

Bowsher, C. G. (2007). Modelling Security Market Events in Continous Time: Intensity Based, Multivariate Point Process Models. Journal of Econometrics, 141(2):876-912.

Brown, T. C. and Nair, M. G. (1988). A Simple Proof of the Multivariate Random Time Change Theorem for Point Processes. Journal of Applied Probability, 25(1):210-214.

Chlistalla, M. and Lutat, M. (2011). Competition in Securities Markets: The Impact on Liquidity. Financial Markets and Portfolio Management, 25(2):149-172.

Chordia, T., Roll, R., and Subrahmanyam, A. (2000). Commonality in Liquidity. Journal of Financial Economics, 56(1):3 - 28.

Chordia, T., Roll, R., and Subrahmanyam, A. (2001). Market Liquidity and Trading Activity. The Journal of Finance, 56(2):501 - 530.

Degryse, H., de Jong, F., and van Kervel, V. (2011). The Impact of Dark Trading and Visible Fragmentation on Market Quality. Working Paper.

Engle, R. and Russell, J. (1997). Forecasting the Frequency of Changes in Quoted Foreign Exchange Prices with the Autoregressive Conditional Duration Model. Journal of Empirical Finance, 4(2-3):187-212.

Engle, R. F. and Granger, C. W. J. (1987). Co-Integration and Error Correction: Representation, Estimation, and Testing. Econometrica, 55(2):251276. 
Engle, R. F. and Russell, J. R. (1998). Autoregressive Conditional Duration: A New Model for Irregularly Spaced Transaction Data. Econometrica, 66(5):1127-1162.

Eubank, R. and Speckman, P. (1990). Curve Fitting by PolynomialTrigonometric Regression. Biometrika, 77(1):1-9.

Foucault, T. and Menkveld, A. J. (2008). Competition for Order Flow and Smart Order Routing Systems. The Journal of Finance, 63(1):119-158.

Grammig, J. and Peter, F. J. (2011). Tell-Tale Tails: A New Approach to Estimating Unique Market Information Shares. Journal of Financial and Quantitative Analysis, forthcoming.

Gresse, C. (2010). Multi-Market Trading and Market Liquidity. Working Paper.

Hall, A. D. and Hautsch, N. (2006). Order Aggressiveness and Order Book Dynamics. Empirical Economics, 30(4):973-1005.

Hall, A. D. and Hautsch, N. (2007). Modelling the Buy and Sell Intensity in a Limit Order Book Market. Journal of Financial Markets, 10(3):249-286.

Hasbrouck, J. (1995). One Security, Many Markets: Determining the Contribtutions to Price Discovery. The Journal of Finance, 50(4):1175-1199.

Hasbrouck, J. (2002). Stalking the "Efficient Price" in Market Microstructure Specifications: An Overview. Journal of Financial Markets, 5(3):329-339.

Hasbrouck, J. (2003). Intraday Price Formation in U.S. Equity Index Markets. The Journal of Finance, 58(6):2375-2399.

Hendershott, T. and Jones, C. M. (2005). Trade-Through Prohibitions and Market Quality. Journal of Financial Markets, 8(1):1-23.

Hendershott, T., Jones, C. M., and Menkveld, A. J. (2011). Does Algorithmic Trading Improve Liquidity? The Journal of Finance, 66(1):1-33.

Hengelbrock, J. and Theissen, E. (2009). Fourteen at One Blow : The Market Entry of Turquoise. Working Paper.

Hupperets, E. C. and Menkveld, A. J. (2002). Intraday Analysis of Market Integration: Dutch Blue Chips Traded in Amsterdam and New York. Journal of Financial Markets, 5(1):57-82. 
Johansen, S. (1991). Estimation and Hypothesis Testing of Cointegration Vectors in Gaussian Vector Autoregressive Models. Econometrica, 59(6):1551-1580.

Karr, A. (1991). Point Processes and Their Statistical Inference. Dekker, New York.

Kehrle, K. and Peter, F. J. (2011). Who Moves First? An Intensity-Based Measure of Price Discovery across Stock Exchanges. Working Paper.

Kohler, A. and von Wyss, H. (2012). Fragmentation in European Equity Markets and Market Quality - Evidence from the Analysis of Trade-Throughs. Working paper.

O'Hara, M. and Ye, M. (2011). Is Market Fragmentation Harming Market Quality? Journal of Financial Economics, 100(3):459-474.

Riordan, R., Storkenmaier, A., and Wagener, M. (2011). Do Multilateral Trading Facilities Contribute to Market Quality. Working Paper.

Russell, J. R. (1999). Econometric Modelling of Multivariate IrregularlySpaced High-Frequency Data. Working Paper.

Storkenmaier, A. and Wagener, M. (2011). Do we need a European "National Market System"? Competition, Arbitrage, and Suboptimal Executions. Working Paper.

Storkenmaier, A., Wagener, M., and Weinhardt, C. (2012). Public Information in Fragmented Markets. Financial Markets and Portfolio Management, 26(2):179-215.

Tse, Y., Bandyopadhyay, P., and Shen, Y.-P. (2006). Intraday Price Discovery in the DJIA Index Markets. Journal of Business Finance and Accounting, 33(9-10):1572-1585. 


\section{Table 1 - Final Sample}

The table shows the 28 companies contained in our final sample. The sample consists of Swiss stocks that are listed on the Swiss exchange and on Chi-X. MCAP denotes the average daily market capitalization in billion Swiss francs over the first quarter 2010. The full sample is divided into two subsamples, denoted by Stocks $\mathrm{L}$ and Stocks S.

\begin{tabular}{llrr}
\hline Company & Symbol & MCAP & Subsample \\
\hline Nestle & NESN & 188.2 & Stocks L \\
Novartis & NOVN & 150.9 & \\
Roche & ROG & 125.5 & \\
Credit Suisse & CSGN & 59.8 & \\
UBS & UBSN & 56.0 & \\
ABB & ABBN & 48.9 & \\
Zurich Financial Services & ZURN & 36.6 & \\
Syngenta & SYNN & 26.9 & \\
Holcim & HOLN & 24.9 & \\
Swisscom & SCMN & 19.9 & \\
Richemont & CFR & 19.7 & \\
Swiss Re & RUKN & 18.1 & \\
Synthes & SYST & 15.8 & \\
Kuehne + Nagel & KNIN & 12.3 & \\
\hline SGS & SGSN & 11.0 & Stocks S \\
Adecco & ADEN & 10.9 & \\
Swatch Group I & UHR & 9.3 & \\
Givaudan & GIVN & 7.7 & \\
Geberit & GEBN & 7.7 & \\
Actelion & ATLN & 6.7 & \\
Baloise & BALN & 4.6 & \\
Swiss Life Holding & SLHN & 4.4 & \\
Lonza & LONN & 4.3 & \\
Nobel Biocare & NOBN & 3.8 & \\
Logitech & LOGN & 3.4 & \\
Clariant & CLN & 2.8 & \\
Petroplus & PPHN & 1.6 & \\
OC Oerlikon & OERL & 0.5 & \\
\hline & & & \\
& & & \\
& & &
\end{tabular}




\section{Table 2 - Descriptive Statistics}

The table shows descriptive statistics of the number of quote revisions $Q$ and interarrival times $\tau$ in seconds for the thinned process of order arrivals for the Swiss exchange (SWX) and Chi-X (CHI). For the thinning process mean midquote changes per day are calculated and quote changes are retained where the absolute cumulative price change exceeds 50 times the mean midquote change per day. Panel A covers the Pooled Sample and Panel B and Panel C the subsamples Stocks L and Stocks S, respectively. The mean, median, first and third quartile are given over the sample period January 1 to March 31, 2010. Panel D presents the differences in the means and medians between subsamples Stocks L and Stocks S, together with p-values for significant differences between the means and medians, respectively.

\begin{tabular}{|c|c|c|c|c|}
\hline \multicolumn{5}{|c|}{ Panel A: Pooled Sample } \\
\hline & $Q^{\mathrm{SWX}}$ & $Q^{\mathrm{CHI}}$ & $\tau^{\mathrm{SWX}}$ & $\tau^{\mathrm{CHI}}$ \\
\hline Mean & 1,542 & 1,379 & 2,081 & 3,337 \\
\hline Median & 1,223 & 1,179 & 1,687 & 2,942 \\
\hline Q75 & 1,925 & 1,587 & 2,827 & 4,423 \\
\hline Q25 & 830 & 574 & 1,016 & 2,010 \\
\hline \multicolumn{5}{|c|}{ Panel B: Stocks L } \\
\hline & $Q^{\mathrm{SWX}}$ & $Q^{\mathrm{CHI}}$ & $\tau^{\mathrm{SWX}}$ & $\tau^{\mathrm{CHI}}$ \\
\hline Mean & 1,997 & 1,785 & 2,017 & 3,405 \\
\hline Median & 1,864 & 1,511 & 1,054 & 2,603 \\
\hline Q75 & 2,924 & 2,007 & 3,272 & 4,931 \\
\hline Q25 & 982 & 561 & 805 & 1,741 \\
\hline \multicolumn{5}{|c|}{ Panel C: Stocks S } \\
\hline & $Q^{\mathrm{SWX}}$ & $Q^{\mathrm{CHI}}$ & $\overline{\tau^{\mathrm{SWX}}}$ & $\tau^{\mathrm{CHI}}$ \\
\hline Mean & 1,087 & 973 & 2,145 & 3,270 \\
\hline Median & 1,049 & 1,139 & 2,068 & 2,942 \\
\hline Q75 & 1,308 & 1,249 & 2,819 & 4,353 \\
\hline Q25 & 823 & 587 & 1,491 & 2,474 \\
\hline \multicolumn{5}{|c|}{ Panel D: Diff. Stocks L - Stocks S } \\
\hline & $Q^{\mathrm{SWX}}$ & $Q^{\mathrm{CHI}}$ & $\tau^{\mathrm{SWX}}$ & $\tau^{\mathrm{CHI}}$ \\
\hline Mean & 910 & 812 & -128 & 135 \\
\hline $\mathrm{p}$-value & 0.02 & 0.11 & 0.82 & 0.84 \\
\hline Median & 815 & 372 & $-1,014$ & -339 \\
\hline p-value & 0.06 & 0.18 & 0.12 & 0.60 \\
\hline
\end{tabular}




\section{Table 3 - Hasbrouck Information Shares}

The table shows the average daily mean, median, first and third quartile of the Hasbrouck information shares (HIS) together with the upper and lower bounds $\left(H I S_{\text {up }}\right.$ and $\left.H I S_{\text {low }}\right)$ for the Swiss exchange (SWX) and for Chi-X (CHI) over the sample period January 1 to March 31, 2010. Panel A covers the Pooled Sample and Panel B and Panel C the subsamples Stocks L and Stocks S, respectively. The information shares are calculated as daily means of the upper and lower bound.

\begin{tabular}{|c|c|c|c|c|c|c|}
\hline \multicolumn{7}{|c|}{ Panel A: Pooled Sample } \\
\hline & $H I S^{\mathrm{SWX}}$ & $H I S^{\mathrm{CHI}}$ & $H I S_{u p}^{\mathrm{sWX}}$ & $H I S_{u p}^{\mathrm{CHI}}$ & $H I S_{\text {low }}^{\text {SWX }}$ & $H I S_{\text {low }}^{\mathrm{CHI}}$ \\
\hline Mean & $53.25 \%$ & $46.75 \%$ & $66.04 \%$ & $59.53 \%$ & $40.47 \%$ & $33.96 \%$ \\
\hline Median & $48.16 \%$ & $51.84 \%$ & $63.94 \%$ & $67.55 \%$ & $32.45 \%$ & $36.06 \%$ \\
\hline Q75 & $67.62 \%$ & $63.50 \%$ & $77.49 \%$ & $81.23 \%$ & $58.80 \%$ & $45.87 \%$ \\
\hline Q25 & $36.50 \%$ & $32.38 \%$ & $54.13 \%$ & $41.20 \%$ & $18.77 \%$ & $22.51 \%$ \\
\hline \multicolumn{7}{|c|}{ Panel B: Stocks L } \\
\hline & $H I S^{\mathrm{sWX}}$ & $H I S^{\mathrm{CHI}}$ & $H I S_{u p}^{\mathrm{sWX}}$ & $H I S_{u p}^{\mathrm{CHI}}$ & $H I S_{\text {low }}^{\mathrm{SWX}}$ & $H I S_{\text {low }}^{\mathrm{CHI}}$ \\
\hline Mean & $44.12 \%$ & $55.88 \%$ & $60.33 \%$ & $72.08 \%$ & $27.92 \%$ & $39.67 \%$ \\
\hline Median & $41.34 \%$ & $58.66 \%$ & $58.87 \%$ & $75.92 \%$ & $24.08 \%$ & $41.13 \%$ \\
\hline Q75 & $51.65 \%$ & $67.23 \%$ & $68.21 \%$ & $85.44 \%$ & $35.74 \%$ & $49.10 \%$ \\
\hline Q25 & $32.77 \%$ & $48.35 \%$ & $50.90 \%$ & $64.26 \%$ & $14.56 \%$ & $31.79 \%$ \\
\hline \multicolumn{7}{|c|}{ Panel C: Stocks S } \\
\hline & $H I S^{\mathrm{swX}}$ & $H I S^{\mathrm{CHI}}$ & $H I S_{u p}^{\mathrm{SWX}}$ & $H I S_{u p}^{\mathrm{CHI}}$ & $H I S_{\text {low }}^{\mathrm{SWX}}$ & $H I S_{\text {low }}^{\mathrm{CHI}}$ \\
\hline Mean & $62.38 \%$ & $37.62 \%$ & $71.74 \%$ & $46.98 \%$ & $53.02 \%$ & $28.26 \%$ \\
\hline Median & $60.92 \%$ & $39.08 \%$ & $71.96 \%$ & $49.07 \%$ & $50.93 \%$ & $28.04 \%$ \\
\hline Q75 & $81.86 \%$ & $55.73 \%$ & $86.46 \%$ & $71.10 \%$ & $78.18 \%$ & $41.15 \%$ \\
\hline Q25 & $44.27 \%$ & $18.14 \%$ & $58.85 \%$ & $21.82 \%$ & $28.90 \%$ & $13.54 \%$ \\
\hline
\end{tabular}






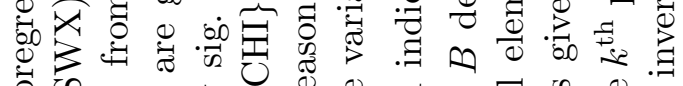

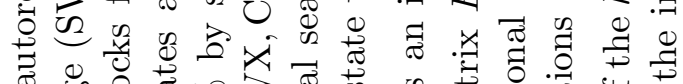

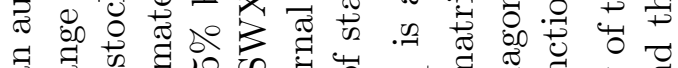

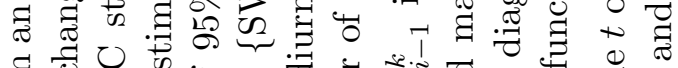

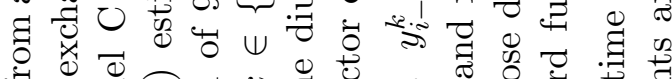

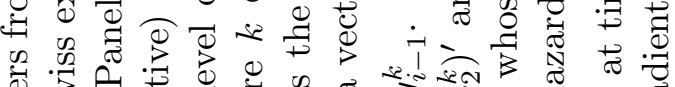

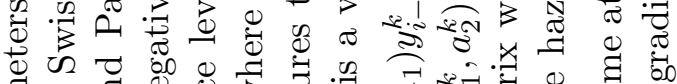

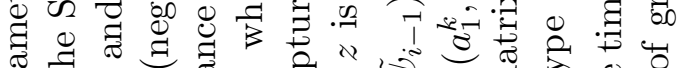
สై

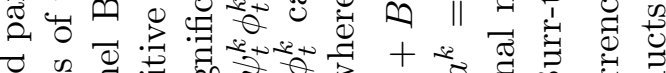
ఫै

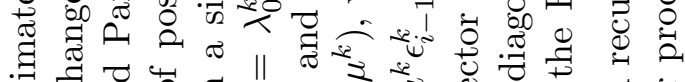

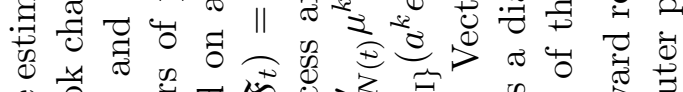

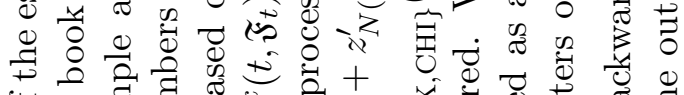

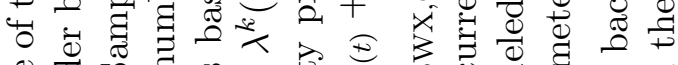

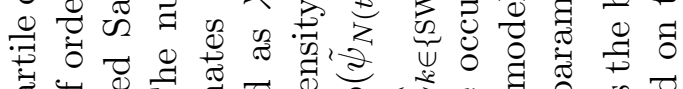

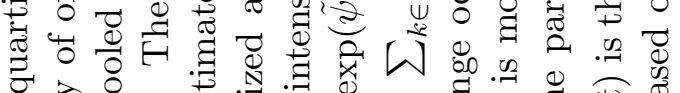

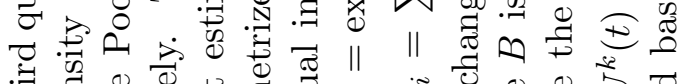

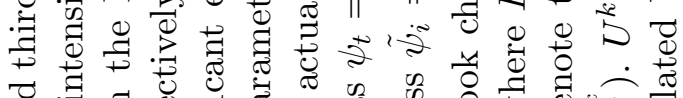

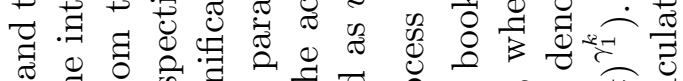

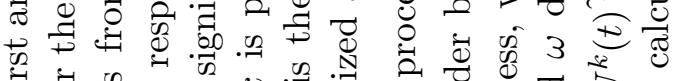

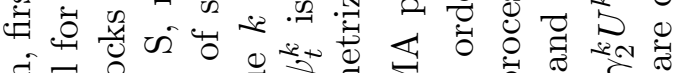

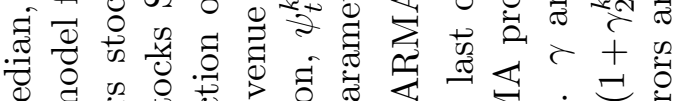

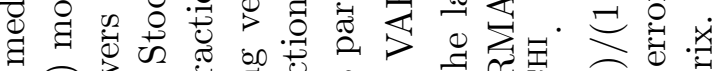

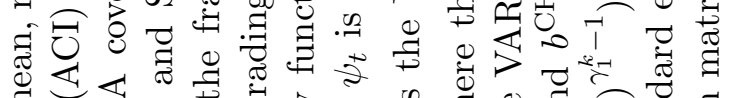

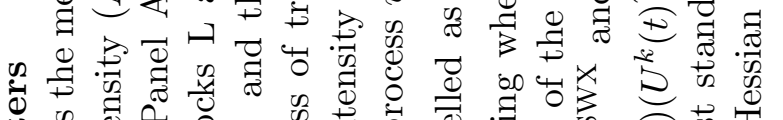

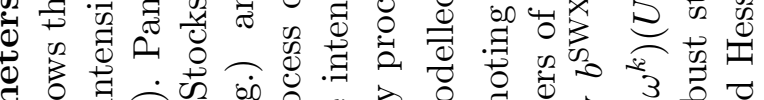

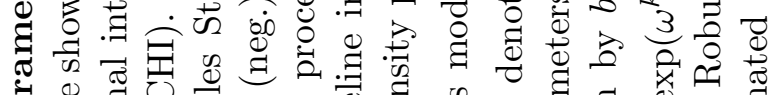

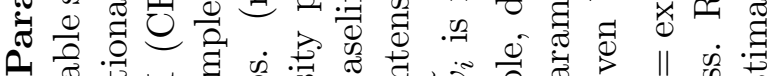

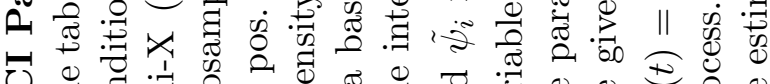

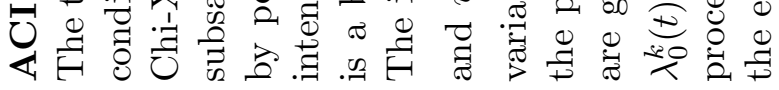






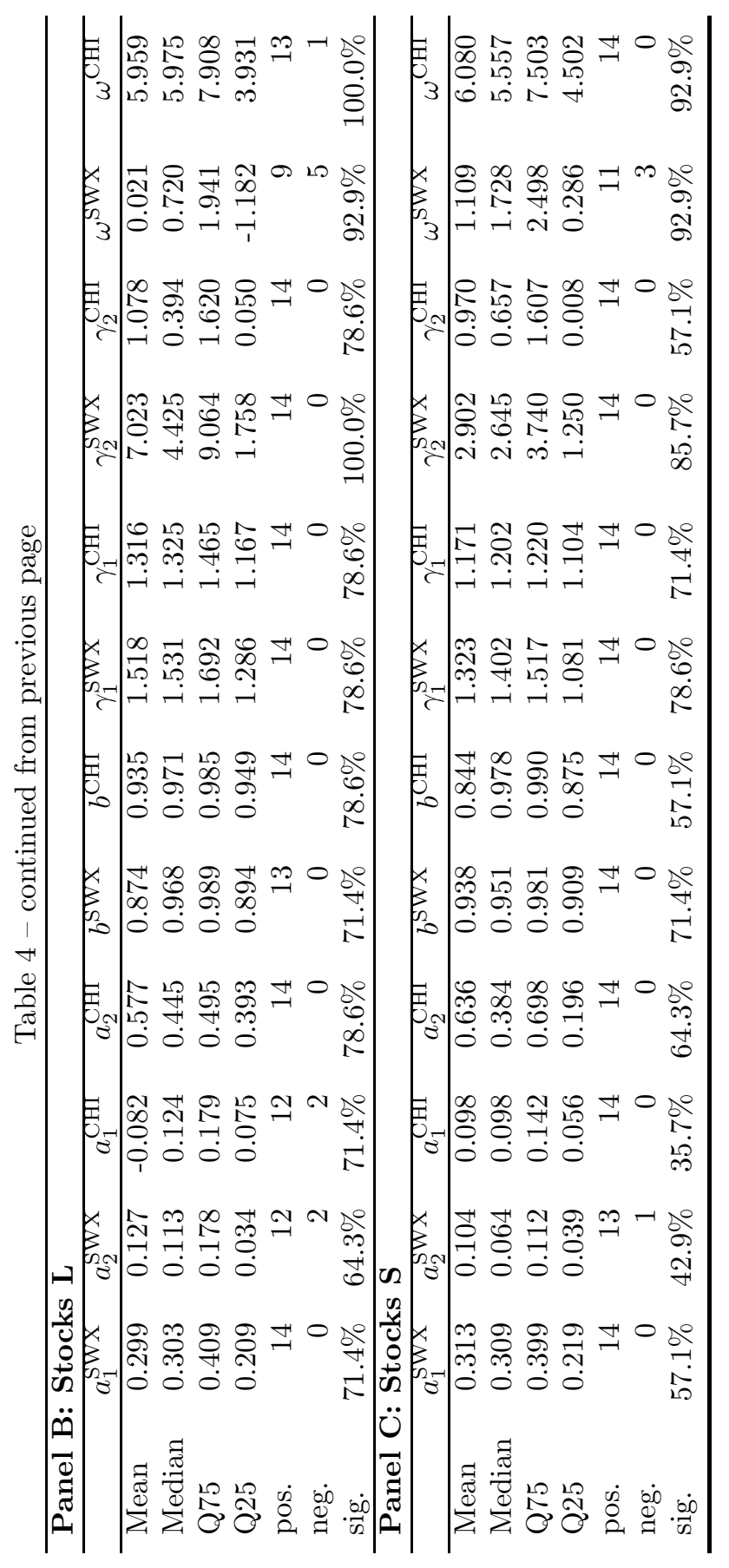




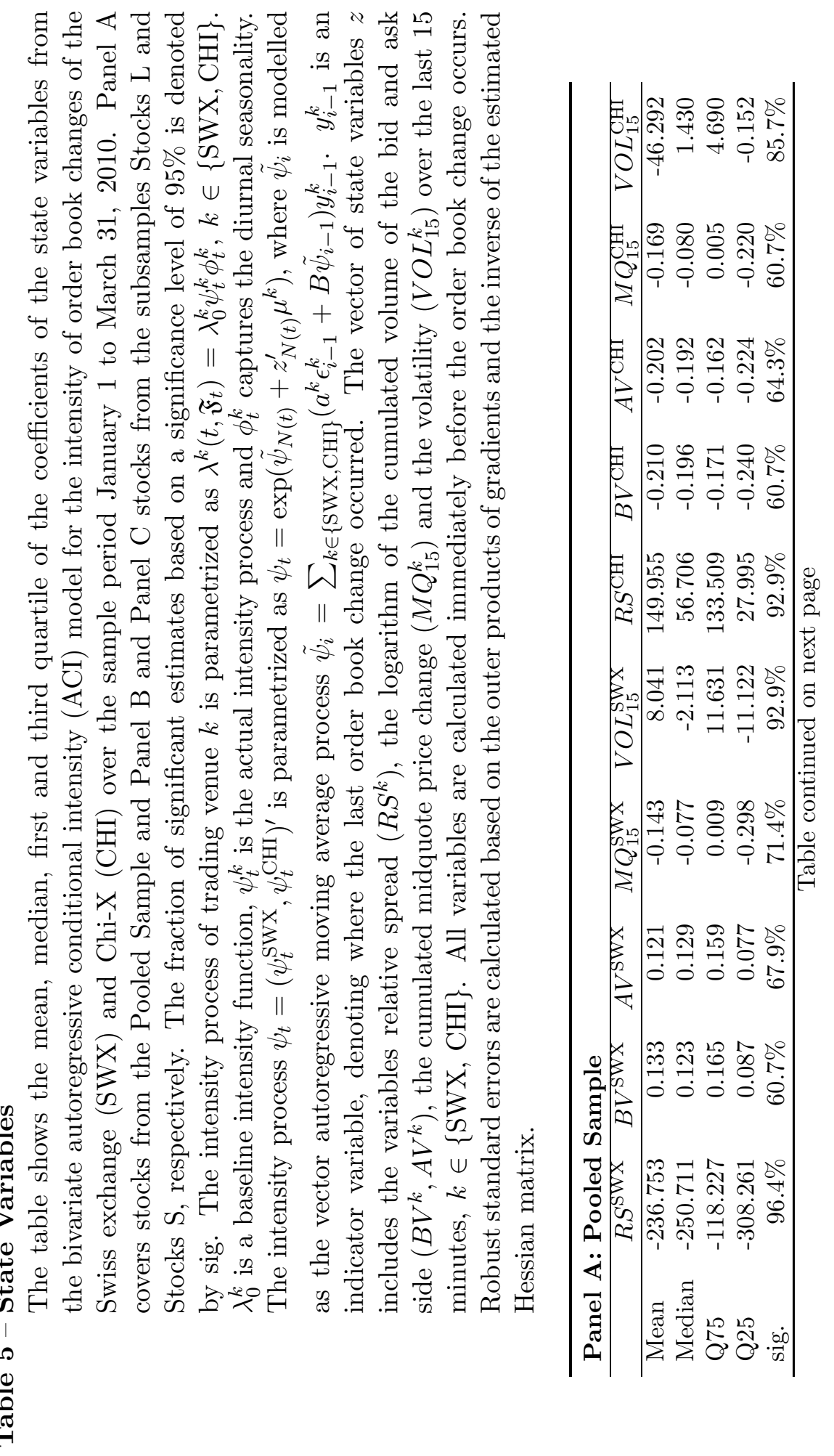




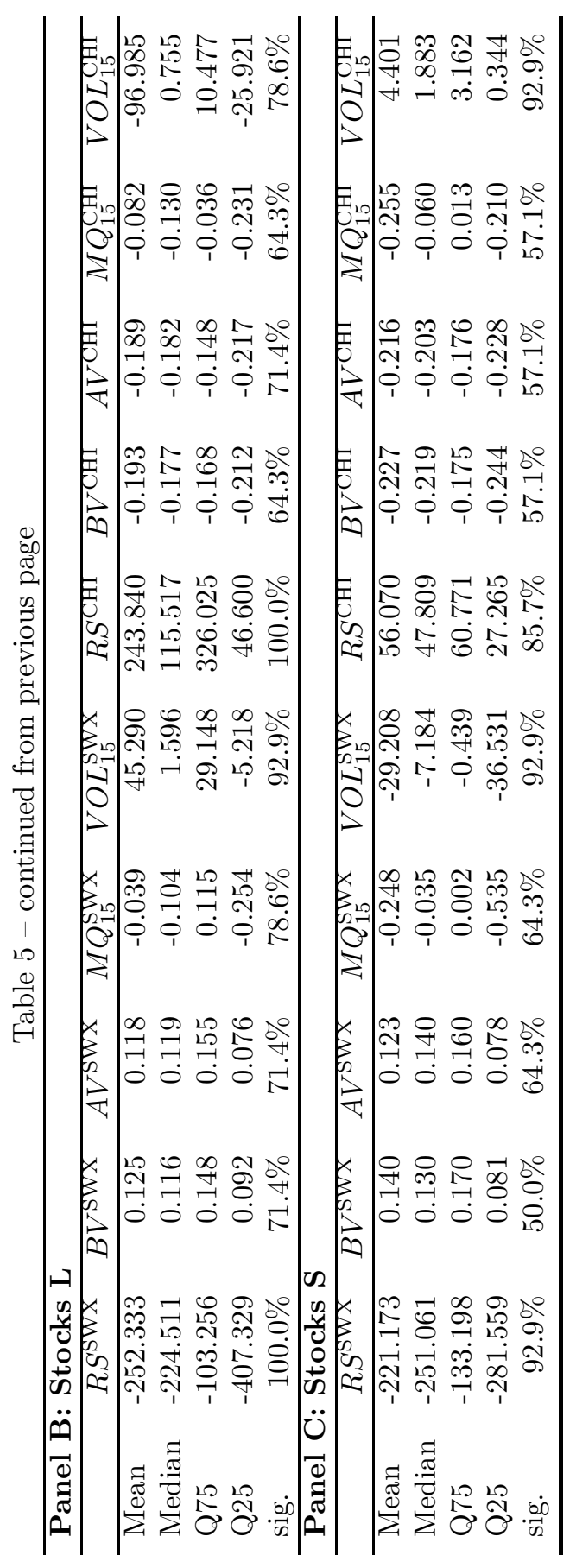




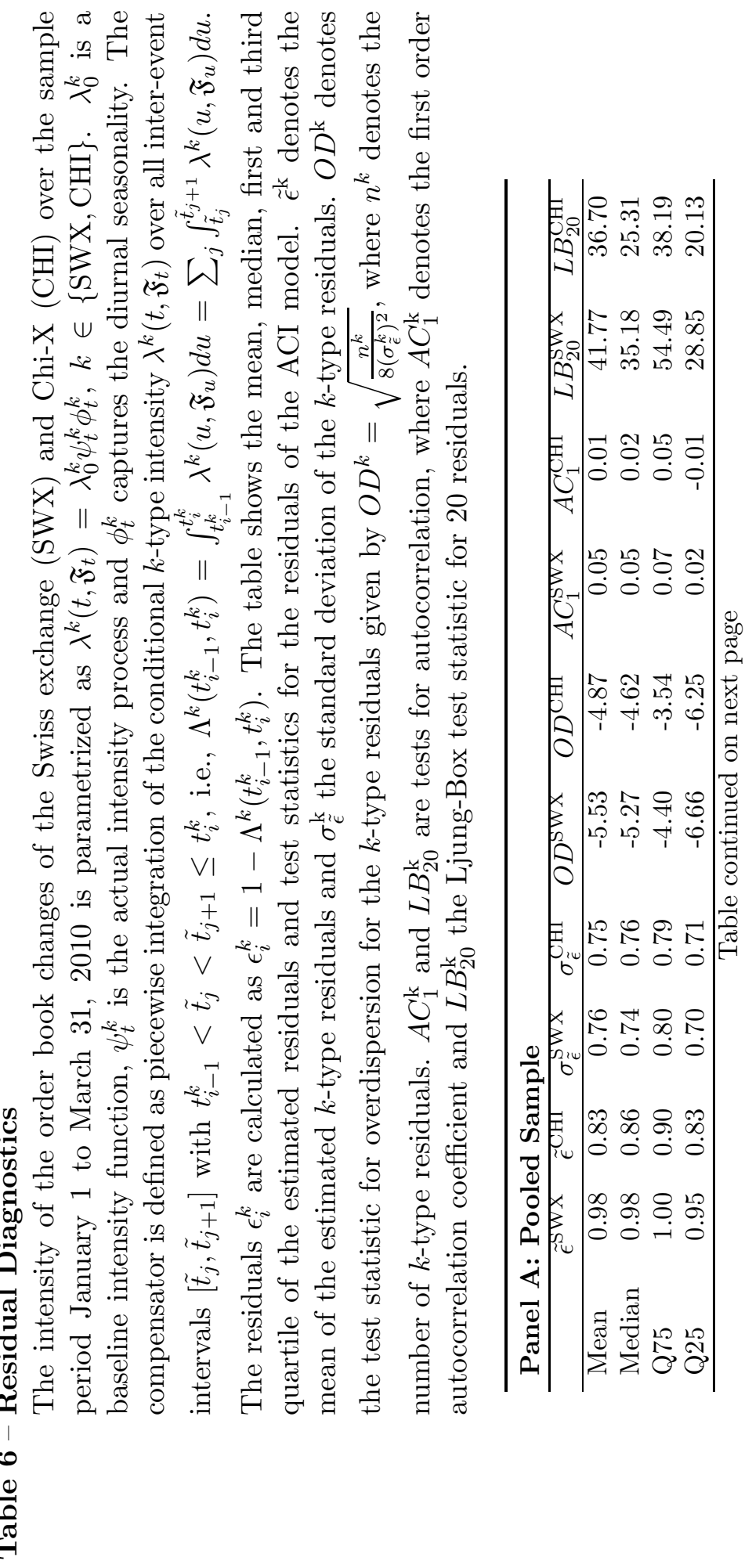




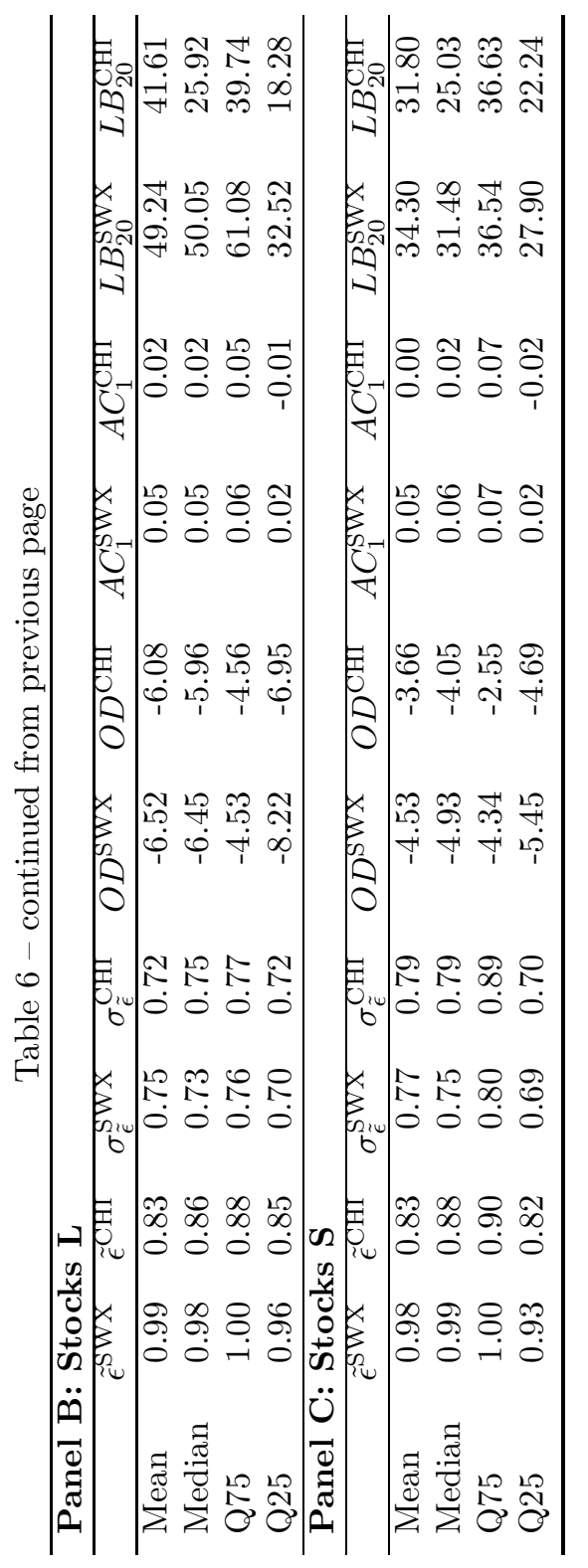




\section{Table 7 - Intensity Based Information Shares}

The table shows the intensity based information shares $I I S^{\mathrm{SWX}}=$ $\frac{\frac{\left|a_{2}^{\mathrm{SWX}}\right|}{\left|a_{2}^{\mathrm{CHI}}\right|}}{\frac{\left|a_{1}^{\mathrm{CHI}}\right|}{\left|a_{1}^{\mathrm{SWX}}\right|}+\frac{\left|a_{2}^{\mathrm{SWX}}\right|}{\left|a_{2}^{\mathrm{CHI}}\right|}}$ and $\quad I I S^{\mathrm{CHI}}=\frac{\frac{\left|a_{1}^{\mathrm{CHI}}\right|}{\left|a_{1}^{\mathrm{SWX}}\right|}}{\frac{\left|a_{1}^{\mathrm{CHI}}\right|}{\left|a_{1}^{\mathrm{SWX}}\right|}+\frac{a_{2}^{\mathrm{SWX}} \mid}{\left|a_{2}^{\mathrm{CHI}}\right|}}$, where the parameters $a_{1}^{k}$ and $a_{2}^{k}, k \in\{\mathrm{SWX}, \mathrm{CHI}\}$, are estimates from the bivariate autoregressive conditional intensity (ACI) model for the intensity of order book changes of the Swiss exchange (SWX) and Chi-X (CHI) over the sample period January 1 to March 31, 2010. Panel A covers stocks from the Pooled Sample and Panel B and Panel C stocks from the subsamples Stocks L and Stocks S, respectively. Lead $95 \%$ and Lead $99 \%$ denote the fraction of stocks in the respective subsamples, where the intensity based information share of one market is significantly higher than $50 \%$ with a confidence level of $95 \%$ and $99 \%$, respectively.

\begin{tabular}{|c|c|c|}
\hline \multicolumn{3}{|c|}{ Panel A: Pooled Sample } \\
\hline & $I I S^{\mathrm{SWX}}$ & $I I S^{\mathrm{CHI}}$ \\
\hline Mean & $36.6 \%$ & $63.4 \%$ \\
\hline Median & $33.6 \%$ & $66.4 \%$ \\
\hline Q75 & $52.8 \%$ & $83.7 \%$ \\
\hline Q25 & $16.3 \%$ & $47.2 \%$ \\
\hline Lead $95 \%$ & $7.1 \%$ & $46.4 \%$ \\
\hline Lead $99 \%$ & $3.6 \%$ & $42.9 \%$ \\
\hline \multicolumn{3}{|c|}{ Panel B: Stocks L } \\
\hline & $I I S^{\mathrm{SWX}}$ & $I I S^{\mathrm{CHI}}$ \\
\hline Mean & $37.6 \%$ & $62.4 \%$ \\
\hline Median & $42.1 \%$ & $57.9 \%$ \\
\hline Q75 & $57.3 \%$ & $84.0 \%$ \\
\hline Q25 & $16.0 \%$ & $42.7 \%$ \\
\hline Lead $95 \%$ & $14.3 \%$ & $57.1 \%$ \\
\hline Lead $99 \%$ & $7.1 \%$ & $57.1 \%$ \\
\hline \multicolumn{3}{|c|}{ Panel C: Stocks S } \\
\hline & $I I S^{\mathrm{SWX}}$ & $I I S^{\mathrm{CHI}}$ \\
\hline Mean & $35.6 \%$ & $64.4 \%$ \\
\hline Medial & $31.1 \%$ & $68.9 \%$ \\
\hline Q75 & $44.6 \%$ & $83.3 \%$ \\
\hline Q25 & $16.7 \%$ & $55.4 \%$ \\
\hline Lead $95 \%$ & $0.0 \%$ & $35.7 \%$ \\
\hline Lead $99 \%$ & $0.0 \%$ & $28.6 \%$ \\
\hline
\end{tabular}




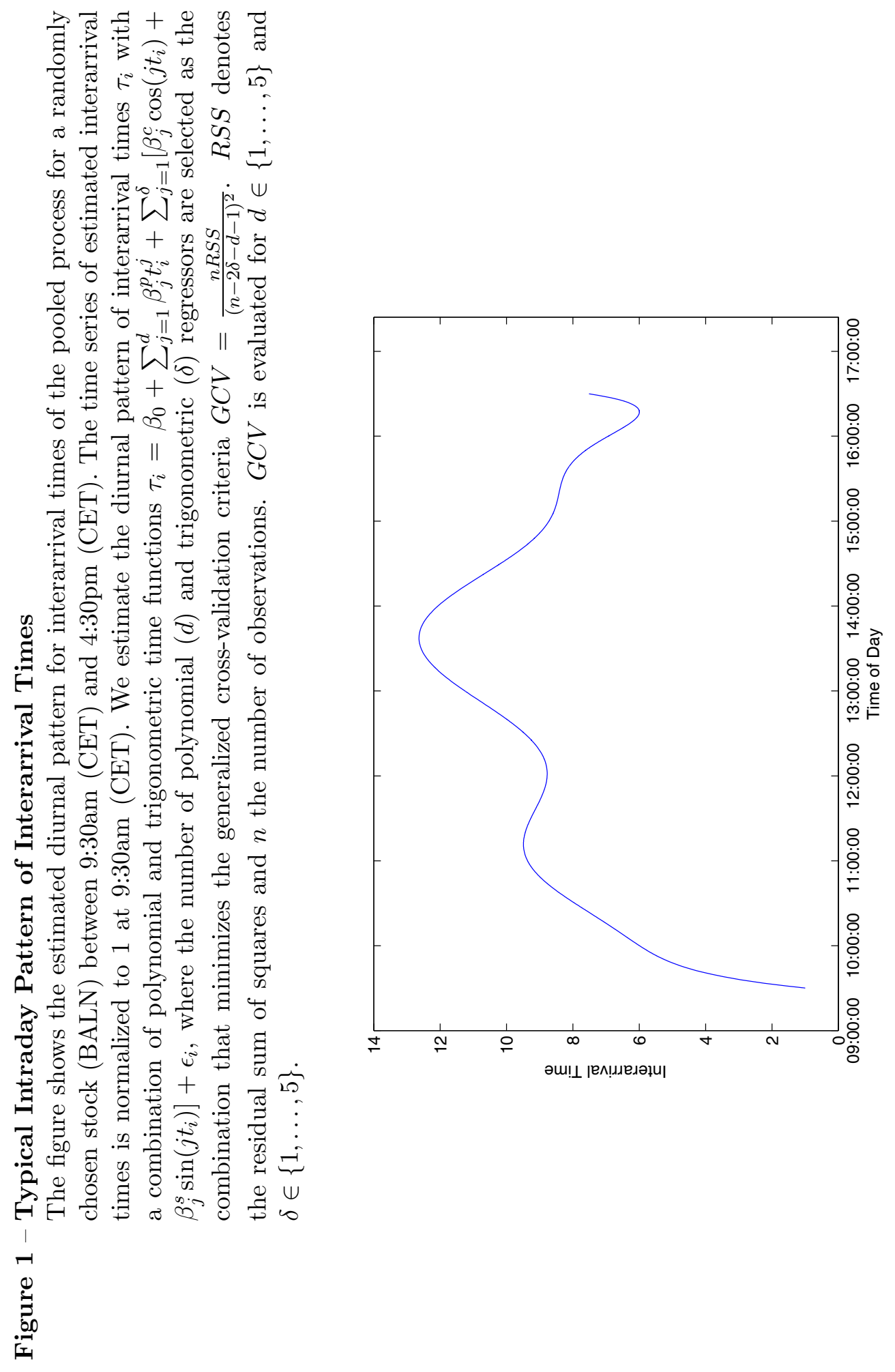






